\title{
Confianza y eficacia ciudadana en una sociedad con alta desigualdad
}

\author{
Víctor Manuel Durand Ponte \\ Instituto de Investigaciones Sociales \\ Universidad Autónoma de México
}

\begin{abstract}
Resumo
O artigo busca analisar para o caso mexicano a relação entra a eficácia cidadã, definida como a percepção pelos cidadãos de sua capacidade de influência na solução de seus problemas, no curso das instituições e na confiança nas instituições públicas. A hipótese é que a confiança é um processo que se cons. trói na experiência cotidiana da vida pública do cidadão e para desenvolvê-la utiliza dados de pesquisas da Secretaria de Governo de 2000 e 2003.
\end{abstract}

Palavras-chave: cidadania, confiança, instituições públicas, México

\section{Resumen}

El articulo intenta analizar para el caso mexicano la relación entre la eficacia ciudadana, definida como la percepción de los ciudadanos de su capacidad de influencia en la solución de sus problemas y en el rumbo de las instituciones y la confianza en las instituciones públicas. La hipótesis es que la confianza es un proceso que se construye en la experiencia cotidiana de la vida pública del ciudadano y se servirá de los datos de las encuestas de la Secretaría de Gobernación de 2000 y 2003.

Palabras-clave: ciudadania, confianza, instituciones públicas, Mexico 


\section{Introducción}

El incremento en el interés por el tema de la confianza interpersonal y en las instituciones se debe, al menos en parte, a la crisis que experimentan los regimenes democráticos en el mundo, crisis de participación de los ciudadanos en los procesos políticos (NORRIS, 2002), crisis de representación de la sociedad en las distintas instancias del estado (ROSANVALON, 2004), crisis de asociativismo, pérdida del capital social (PUTNAM, 2002 y 2003), pérdida de apoyo político (DALTON, 2005 ) $y$, en general, a la pérdida de eficacia de las instituciones políticas para garantizar la gobernabilidad y la gobernanza (BECK, 2000 y 2002; BAUMAN, 2000 ; HARDT y NEGRI, 2004; CASTEL, 2001).

En este proceso desalentador el aporte de Putnam (1993), en torno al papel que el capital social desempeñó en la democracia del norte de Italia, avivó el interés en la importancia de sus dos componentes básicos; por una parte la confianza interpersonal y, por la otra, la reciprocidad. La tesis de que por medio del aumento del capital social se fortalecería a los regímenes democráticos al incrementar la participación ciudadana en los procesos políticos y con el aumento de la eficacia ciudadana cobró fuerza y se tradujo en una infinidad de programas para impulsar la creación de capital social y apoyar el existente.

Sin embargo, después de varios años la realidad muestra una profundización de la crisis política y una mayor pérdida de capital social y de la confianza, sobre todo entre los sectores marginales o excluidos (PUTNAM, 2003) ${ }^{1}$. Al parecer no podemos salir del planteamiento inicial: ¿cómo fortalecer los regímenes democráticos, cómo consolidar las democracias emergentes?

En lugar de continuar insistiendo en esos recursos, quizás hay que replantear la pregunta ¿es posible fortalecer la democracia en las sociedades actuales?

La reflexión que presentamos en esta ponencia se enmarca en esta problemática, pero se restringe a la relación entre la confianza y la eficacia política en una sociedad con muy alta desigualdad social.

\footnotetext{
1 De acuerdo con los resultados de la Encuesta Mundial de Valores la desconfianza hacia las personas aumento de $60 \%$ en 1990 a $68 \%$ en 1997, en el 2000 subio al $77 \%$ y alcanzó el $84 \%$ en el año 2005 , entre los 8 años extremos la desconfianza se incrementó en 24 puntos porcentuales contrariando su relación con la democracia. Reforma, 15 de enero de 2006, Nacional, p. 4.
} 
PONTE, V. M. D. Confianza y eficacia ciudadana en una sociedad con alta desigualdad

\section{Los conceptos}

En los estudios sobre la confianza destacan ciertos elementos que podemos considerar como anclas o puntos de apoyo de cualquiera análisis; de ellos nos interesan dos.

Primero, que la confianza no se opone a la desconfianza como lo racional a lo irracional, o lo bueno a lo malo; tanto la confianza como la desconfianza pueden ser racionales en momentos, espacios y temas determinados y también pueden ser buenos o malos; tanto la confianza como la desconfianza pueden reducir la complejidad de sistemas y reducir la incertidumbre inherente a la acción, son equivalentes funcionales. Por qué entonces se da tanta preferencia a la confianza frente a la desconfianza; nos parece que Luhmann (1996) tiene razón cuando afirma que la confianza garantiza un mejor funcionamiento tanto interno, como con su entorno, de los sistemas, incluyendo, por supuesto, el sistema de la personalidad. En sus palabras "La confianza es racional con respecto a la función de aumentar el potencial de un sistema para la complejidad. Sin la confianza solamente son posibles formas muy simples de cooperación humana, las que pueden llevarse a cabo en el lugar, e incluso la acción individual es demasiado sensible al rompimiento para que se pueda plantear sin la confianza, más allá del momento inmediatamente asegurado. La confianza es indispensable con el propósito de aumentar el potencial de un sistema social para la acción más allá de estas formas elementales" (1996, p. 154).

La desconfianza se vuelve necesaria cuando ese funcionamiento no está garantizado o la relación de los sistemas con el entorno es disfuncional y conflictivo. Cuando los sistemas no están bien diferenciados, no son del todo autónomos, entonces su relacionamiento crea desorden, intromisión, corrupción. Esto vale tanto para la relación entre el sistema económico y el político, como para el sistema de personalidad con el político (DE GEORGI, 1998). En esos casos, la desconfianza aparece como mejor opción. Ciertamente la desconfianza resta potencialidad al sistema, reduce el ámbito de las relaciones tanto en el tiempo y en el espacio, pero crea la certidumbre necesaria en condiciones de reciprocidad débil o poco previsible.

Segundo, la confianza se inicia con la existencia de la libertad, de la capacidad del actor de elegir libremente, incluso si corresponde o no actuar con base en ella; por lo tanto, en sociedades o ámbitos cerrados, donde la comunidad se impone a los individuos, ni la confianza ni la desconfianza tiene alguna función o sentido. Por ello, la familiaridad es distinta de la confianza y por más que pueda estar en su origen son dos elementos diferentes de la interacción social. En una comunidad indígena muy poco diferenciada, al igual que en la familia, la normatividad, las reglas y la autoridad tradicionales reducen drásticamente la libertad de elección, aunque por supuesto no la anulan, pero nadie se pregunta si debe confiar o desconfiar de los demás miembros, aunque sí de los otros, de los extraños. Justamente en 
la relación con los otros es que el tema de la confianza o la desconfianza se inicia o cobra importancia.

Un elemento estrechamente ligado a la libertad de los individuos es la garantía de que sus actos, sus decisiones, serán respetados, siempre y cuando no violen los derechos de otros actores; dicha garantía no sólo está asegurado por el estado de derechos por el gobierno y su capacidad de aplicar sanciones a quienes violen la ley, sino también por una sociedad civil que obligue, que exija, al estado el cumplimiento de su función y su no intromisión en la libertad de las personas. Si el estado de derecho no funciona o lo hace de manera imperfecta, la libertad se restringe: unos son "más libres" que otros, hasta el grado de gozar de impunidad y violar la ley de acuerdo a sus intereses. Ante la falta de garantías para el ejercicio de la libertad, ante la ambigüedad en la aplicación de la ley y la justicia, la desconfianza es más racional, la confianza parece como una actitud inocente o suicida.

La confianza tiene varios destinatarios: se puede referir a uno mismo, es decir, la autoconfianza en la interacción con otras personas; la confianza interpersonal, ya sea cara a cara o a distancia, y la confianza en las instituciones o en los sistemas expertos. Desatendiendo la autoconfianza, cuyas implicaciones no son relevantes para el desarrollo de este trabajo, tanto la confianza en las otras personas, como la que se refiere a las instituciones tienen dos fuentes principales: la normativa y el desempeño. En el primer caso, la norma indica lo que se debe hacer, confiar o desconfiar; la ley dice que la policía está para cuidad a los ciudadanos, lo mismo que los jueces están para impartir justicia. En el plano normativo integramos los prejuicios y las tradiciones que influyen en la determinación de la confianza o la desconfianza, como el prejuicio negativo a los marginales, los indígenas, de género o a los extraños, extranjeros y, en el caso opuesto, el prejuicio positivo que se da a ciertos roles como los sacerdotes o los maestros, etcétera, que definen relaciones de confianza o de desconfianza; en el segundo, el desempeño indica un nivel experto, sólo ahí se sabe como hacer o desempeñar algún rol, o bien los resultados de la acción indican que lo hace racionalmente de acuerdo con los fines que le son propios. Se debe confiar en el mecánico, en el médico, en el maestro, en el piloto del avión, porque ellos son expertos; salvo que sus historial, o su desempeño, indique lo contrario, el médico es un charlatán, el piloto tiene malos antecedentes, etcétera.

En general, la confianza o la desconfianza en las personas o en las instituciones son el resultado de ambos criterios: normativo y desempeño.

Como se desprende de lo anterior la certeza o la ambigüedad son posibles: el juez que debe garantizar la justicia, el proceso debido, el juicio justo, puede corresponder a la realidad o no, en la práctica el juez puede ser corrupto, favorece a los poderosos y a los ricos, etcétera. Por ello la confianza es siempre producto de la experiencia, de un aprendizaje: aunque tenga bases normativas no se puede confiar en un juez corrupto, no sólo es un error sino un riesgo, pero no es tan simple, pues 
PONTE, V. M. D. Confianza y eficacia ciudadana en una sociedad con alta desigualdad

el juez o los jueces pueden ser erráticos, ambiguos, en ocasiones actúan correctamente, en otras no, ¿cómo saber cuándo y en qué confiar y cuándo no? Para la per. sona la ambigüedad implica un aumento de la complejidad y sólo la desconfianza la puede reducir.

La relación entre la confianza en las instituciones políticas y a eficacia ciudadana se inscribe en este marco, la eficacia ciudadana en cuanto evalúa el desem. peño de las instituciones y de los políticos, así como su capacidad para intervenir en ellos -en estar representado, ser tomado en cuenta en sus intereses y demandas. es un antecedente o un corrector de la confianza depositada en las instituciones y en los funcionarios públicos, aunque obviamente su efectos no son mecánicos o automáticos, pues hay otros factores que también influyen.

Entre esos últimos factores están los afectivos a los cuales no hemos hecho referencia, el orgullo nacional, el amor a la patria, el apego a los logros de la histo. ria, el cariño por los sacerdotes, el miedo a la condena. La afectividad puede anular los criterios normativos y evaluativos, pero esta anulación suprime la libertad, la reduce a un sentimiento que preferimos no confundir con la confianza o la descon. fianza.

El concepto de eficacia ciudadana se refiere a la relación entre el ciudadano y el sistema. La eficacia o la competencia ciudadana como la llamaron Almond y Verba (1963) implica la clara diferenciación entre el sistema político y el de la per. sonalidad, como también con la sociedad, en especial la sociedad organizada civilmente. La eficacia ciudadana es propia sólo de los regímenes democráticos, ahí donde los individuos tienen derechos que el estado no puede violar, garantías indi. viduales en las cuales basan su independencia y autonomía frente al estado. La eficacia ciudadana se refiere entonces a esa certidumbre que da el efectivo funcionamiento del estado de derecho, solo ahí encontramos una generalización de la efica. cia entre la mayoría de los ciudadanos. En regímenes autoritarios, como el que vivió México en los setenta años que dominó del PRI, algunos ciudadanos pueden sentirse y de hecho ser eficaces, tienen la capacidad de influir en el gobierno, de hacer respetar sus intereses, pero son siempre una minoría definida por diferentes razo. nes como el influyentismo, las disposición de relaciones sociales o políticas con los poderosos, el conocimiento de sus derechos y su lucha por hacerlos respetar, pero no es un producto siempre predecible como en el caso de las democracias que fun. cionan con un estado de derecho pleno. En nuestras realidades debemos esperar que la eficacia ciudadana esté a medio camino entre el estado de derecho y la arbi. trariedad que define su ausencia, es el estado de transición o de consolidación. Existe una dimensión afectiva de la eficacia que sale del enfoque de la acción racio. nal o calculada, que responde a compromisos emocionales del actor, que se identifica con el sistema al margen de la evolución, esta dimensión estuvo presente en el 
viejo régimen y pensamos que aun esta en algunos sectores de la sociedad mexicana.

En la medida en que la eficacia ciudadana es el producto de la evaluación del ciudadano en cuanto tal, en su desempeño frente al sistema político, condensa en su interior una serie de dimensiones como competencias, conocimientos, experiencias y su evaluación, capital humano y social, etcétera, que nos brindan la posibilidad de aproximarnos al conocer el funcionamiento de la relación entre los ciudadanos y el sistema político.

Dentro de la ciencia política la eficacia política de los ciudadanos ha sido limitada por algunos autores (CONVERSE, 1964) que sostiene que los ciudadanos en su gran mayoría, están mal informados y que sus opiniones son cambiantes y hasta contradictorias; que no están estructuradas ideológicamente y que por ello son poco relevantes para el sistema, aun cuando influyan en el mismo por medio de las elecciones. En oposición a este planteamiento elitista clásico encontramos otras interpretaciones que afirman que los ciudadanos en efecto no son expertos y ni es. tán altamente informados en lo relativo al sistema, pero que sí lo están acerca de aquellos asuntos que son de su interés o que afectan sus vidas, sus cotidianos; que no podemos colocar a los ciudadanos en un continuo de mayor a menor competen. cia ciudadana, sino que debemos reconocer que ellos conforman un mosaico, de múltiples públicos con diferentes competencias (MORÁN y BENEDICTO, 1995 ).

El hecho de sentirse un ciudadano eficiente frente al sistema político contempla esa competencia, pero también condiciona el tipo de relación que las personas tienen con el sistema, en este punto es central el tema del apoyo político y el de la confianza. Digámoslo así: si el sistema político no garantiza eficacia política para los ciudadanos, es decir, su entorno, no hay espacio para la confianza; desde luego, esta afirmación requiere del matiz antes apuntado, la eficacia se concentra en aquellos subsistemas en los cuales el ciudadano tiene interés, mucho más que en otros. Sin embargo, la confianza no es un resultado mecánico de la relación (eficacia) de un ciudadano con parte del sistema; es, como veremos, el resultado complejo de un conjunto de relaciones, experiencias, evaluación, etcétera.

La relación entre la eficacia ciudadana y la confianza en las instituciones suponemos que es positiva, a mayor eficacia de los ciudadanos mayor será su confianza en las instituciones y en el sistema político en su conjunto. La confianza interpersonal es un producto más complejo, desde luego influenciado por la relación con el sistema político, pero también por el funcionamiento del resto de la sociedad, desde los grupos primarios y la definición del otro, hasta los sistemas más complejos y abstractos.

La relación entre la eficacia ciudadana y la confianza suponíamos que (después de los procesos de democratización) se iría conformando como un círculo vir. tuoso, mejoraría el funcionamiento del sistema (se haría más autónomo limitando 
las disrupciones provenientes del entorno), logrando mayor transparencia, menor corrupción y, consecuentemente, tendería a mejorar la eficacia ciudadana y generaría confianza en las instituciones. Pero ello no ha sido así, después de la democratización ha habido progresos en la transparencia, pero no en la disminución de la corrupción y tampoco en la eficacia ciudadana y en la confianza. Nuestra hipótesis es que ello responde, al menos en parte, al crecimiento de la desigualdad que se traduce en un entorno que contamina el funcionamiento del sistema político, haciendo que la tendencia sea hacia el funcionamiento de un círculo vicioso o perverso, donde operan otros factores de tipo institucional, como la difícil relación entre los poderes ejecutivo y legislativo o, también, a la formación de una clase política que se convierte en un estamento que cuesta mucho a la sociedad, que impone sus mezquinos intereses al conjunto social. En conjunto estos factores impiden que el estado de derecho se consolide en el país. ${ }^{2}$

El tema de la desigualdad ha sido destacado por una gran cantidad de autores, a manera de ejemplo, para ahorrar tiempo, vale la pena destacar algunos argumentos incluidos en el informe del 2005 del PNUD (2005) sobre el desarrollo humano:

“Desprovistos de bienes públicos, por ejemplo, de información y derechos legales, a los pobres se les niegan oportunidades que les permitan contribuir al crecimiento. Entran en los mercados en términos desiguales y salen de ellos con recompensas también des. iguales.

Las desigualdades extremas también debilitan la legitimidad política y corroen las instituciones pues cuando se dan en el ámbito de los ingresos y las capacidades humanas suelen reflejar disparidades en el poder político. Los grupos desfavorecidos, es decir, los pobres, las mujeres, las poblaciones rurales y las comunidades indígenas, Io son en parte porque su participación política es débil, lo que a su vez se debe a la condición de desventaja social en la que viven.

Asimismo, el informe recupera la oposición entre posturas teóricas acerca de la desigualdad y sus consecuencias "Algunos libertarios niegan la existencia de la justicia social. El teórico del libre mercado F. A. Hayec propuso el famoso argumento de que hablar de una dis-

\footnotetext{
2 Existen ciertos progresos innegables, como la mayor independencia del poder judicial (cuyos magistrados no se sustraen a los vicios de la clase política, en especial los altísimos salarios y las desmedidas prestaciones que se auto-otorgan), la implantación de juicios orales que buscan descongestionar el sis. tema y garantizar una justicia más transparente y expedita, asimismo se ha avanzado en el mejoramien. to de la administración pública y como ya anotamos en la transparencia y en el funcionamiento de una prensa más atenta y crítica de los abusos de las autoridades de los tres poderes. Sin embargo esos progresos son insuficientes para que el sistema funcione, digamos, en automático, sin ambigüedades.
} 
tribución justa o injusta de los recursos es un completo sinsentido. Según su opinión, es el libre mercado y no la intervención de la agencia humana la que debe determinar la correcta repartición de la riqueza y los activos." (p. 60)

Otra opinión muy generalizada es que ciertas desigualdades son más graves que otras y que la igualdad ante la ley es sin duda lo más importante. No obstante los derechos y las libertades. En efecto, es probable que la gente se vea restringida en lo que pueda hacer con sus libertades y derechos si es pobre, está enferma, si se le ha negado educación o carece de la capacidad de influir en lo que le sucede. Para tener sentido, las igualdades formales deben estar respaldadas por lo que Amartya Sen (1999) ha llamado "libertades sustantivas", que consisten en la capacidad de optar por una determinada forma de vida o hacer las cosas que uno valora.

Los argumentos recogidos en el informe nos permiten pensar en tres dimensiones básicas de la desigualdad: la primera es la tendencia a que la desigualdad se reproduzca de manera ampliada, con independencia del crecimiento económico, agregando contingentes sociales a la parte baja y que los grupos marginales o excluidos tiendan a transformarse en un entorno negativo para el fortalecimiento de la democracia, del estado de derecho y de la ciudadanía, agravando la ineficacia ciudadana y destruyendo la confianza interpersonal y en las instituciones.

La dinámica regresiva de la desigualdad social no es sólo un problema cuantitativo, por el contrario implica un cambio cualitativo de la mayor importancia. En la sociedad salarial el pleno empleo era un referente de la economía, el modelo keynesiano se orientaba a su logro y toda la política económica y en especial la intervención del estado por medio del aumento de la demanda buscaba disminuir el desempleo. A partir de la crisis de los años setenta del siglo pasado el crecimiento económico dejó de asociarse con el crecimiento del empleo, más aun, hay una tendencia que muestra que el crecimiento se asocia con una reducción del empleo formal y, consecuentemente con una precarización de los empleos existentes, macjobs. Así junto a la pérdida de la tendencia al pleno empleo, los trabajos formales, es decir, de aquellos que cuentan con la protección de la ley y en los cuales los trabajadores "gozan" de las prestaciones e incluso de estabilidad han dejado de garantizar al trabajador y a su familia una subsistencia digna.

En países en los que no existe el seguro de desempleo, como en México, los trabajadores deben buscar su subsistencia en los ámbitos de la informalidad que crece proporcionalmente a la caída del empleo formal y al aumento de la población económicamente activa. El empleo informal con su falta de garantías y de prestaciones, se asocia con una mayor libertad para buscar el sustento del trabajador y una cantidad mayor de opciones y está llevando a que muchos trabajadores lo prefieran frente al trabajo formal básico, rígido y mal pagado. 
PONTE, V. M. D. Confianza y eficacia ciudadana en una sociedad con alta desigualdad

La segunda dimensión se refiere al carácter total, estructural, de la desigualdad, a la inexistencia de elementos más graves o importantes; la desigualdad es integral y se traduce en círculos viciosos que la reproducen. Por lo tanto, la solución debe considerar este aspecto.

La tercera dimensión es la postura política frente a la desigualdad y las medidas definidas como pertinentes para remediarla. Vimos que hay un enfoque, el liberal (o libertario) en donde se culpa a la víctima, liberando al gobierno y al mercado de cualquier responsabilidad: esta es la postura hegemónica en Estados Unidos y en los organismos internacionales como en FMI y la OMC. También hay otra postura más solidaria, más comunitaria, donde se reconoce que la sociedad y el estado tienen responsabilidades con los más desfavorecidos y que existe la necesidad de la justicia social que disminuya la desigualdad (KOVARICK, 2001). El problema que se coloca, cada vez con mayor crudeza, es que las acciones gubernamentales para favorecer a los desposeídos suelen traducirse en pérdida de competitividad, en aumentos de costos insoportables en el marco del comercio mundial cuyas reglas penalizan los gastos sociales. En la práctica, al final, se impone siempre la posición de los "libertarios".

Las personas que están en la parte inferior de la estructura social, los desafiliados, los inútiles para el capital, los excluidos, simplemente no tienen un futuro de integración por la vía del mercado de trabajo formal; la desigualdad, la vulnerabilidad del trabajador tanto en la formalidad como en la informalidad se convierte en una situación permanente y definitiva, para la mayoría de ellos. La relación entre los integrados y los excluidos es poco permeable por la movilidad ascendente y por ello tiende a la confrontación, a la segregación, a la definición de demandas opuestas, antagónicas, ante el estado.

No se trata de una oposición como la clasista en la que los opuestos se resolvían por la superación o negación de uno de los polos, sino que es una oposición sin superación, destructiva del orden social y de la solidaridad (es pura negatividad).

El comportamiento actual de la desigualdad social es lo que nos obliga a replantear la hipótesis implícita en la democratización que apostaba por el fortalecimiento de la eficacia y de la confianza dentro de un círculo virtuoso. Ahora debemos plantear que dentro de las tendencias actuales la democracia tendrá que sobrevivir dentro de un estado de derecho limitado, con un estado debilitado, incapaz de mantener el orden y de hacer respetar el derecho por todos los ciudadanos. En consecuencia la eficacia ciudadana y la confianza irán a la baja.

La desigualdad y la reunificación política en el México priísta 
La desigualdad en México ha sido un dato siempre presente desde la colonia. Los indígenas y las castas fueron relegados a los estratos más bajos y, en especial las castas, no tenían ningún empleo seguro, eran los excluidos de la época y engrosaban los grupos de léperos, vagos, malvivientes y esto hasta la época de la independencia a principios del siglo XIX. A finales de ese siglo y principios del XX se inició la implantación del capitalismo industrial. Con la Revolución de 1910 se puso fin a la gran propiedad y se repartió la tierra reintegrando a las comunidades indígenas sus tierras comunales y a los campesinos se les dotó de tierras ejidales y en menor medida de tierras en propiedad privada. No obstante, ni el reparto agrario, ni la industrialización y el crecimiento de los servicios fue suficiente para integrar a la mayoría de la población económicamente activa. Como, desde la colonia, una parte importante de la fuerza de trabajo se ganaba la vida en el sector informal, nunca (como en Europa o Estados Unidos y Canadá) se aspiró al pleno empleo, y el estado de bienestar alcanzó apenas a una pequeña parte de la población, a saber, la que trabajaba en la administración pública, en las empresas estatales y en las empresas industriales o de servicios de mediano y gran porte. Entre las políticas públicas ligadas al bienestar sólo la educación alcanzó niveles cercanos al universo. Por cierto que la vida de los léperos y de los vagos mejoró, se integraron a la vida urbana, sus condiciones de educación y salud mejoraron gracias a la seguridad pública; también es cierto que el trabajo y la ética de la responsabilidad permeó al conjunto de la población, pero no dejaron de ser marginales, relegados, en el mejor de los casos, en el sector informal.

La sociedad mexicana, pese al acelerado proceso de urbanización, continuó siendo heterogénea y desigual, era una sociedad que no se integró en el mercado de trabajo formal, sino que lo hizo fundamentalmente por medio de la política. En efecto, ya hemos señalado en otro trabajo (DURAND, 2004) que en el régimen posrevolucionario y en especial, después de 1940, el sistema logró integrar a la población y representarla en al menos tres subregímenes: el ciudadano que se desarrollaba en la ciudades mediante la lucha de partidos de derecha (PAN) y de izquierda (PP, PCM) que junto con la acción de trabajadores de sindicatos que luchaban por la independencia, y de intelectuales comprometidos con la democracia obligaron al PRI a respetar más las elecciones, sin por ello erradicar el fraude; un segundo sub. régimen era el corporativo que agrupaba a los obreros y empleados organizados en los sindicatos y centrales oficiales y también a algunos trabajadores agrícolas; finalmente un vasto sector de la población del campo y de las orillas de las ciudades era integrado en un subrégimen patrimonial controlado por caciques. Cada uno tenía sus reglas de operación, de representación y de participación; todos estaban articulados dentro del PRI. Esa forma de integración de la población al sistema polí. tico garantizó, junto con el crecimiento de la economía, la estabilidad política. 
PONTE, V. M. D. Confianza y eficacia ciudadana en una sociedad con alta desigualdad

Durante el periodo clásico del sistema político mexicano, cuando Almond y Verba realizaron su estudio seminal (1959) pensando que se trataba de una democracia imperfecta, pero democracia al fin, los mexicanos que vivían en las ciudades, confiaban en el estado, en el presidente, pero sobre todo confiaban y estaban orgullosos del pacto popular revolucionario que daba al estado la responsabilidad de atender sobre todo a los pobres, a los campesinos a los trabajadores. En cambio desconfiaban de los políticos a quienes cínicamente consideraban como corruptos, aprovechados, que no honraban la labor del presidente y del pacto revolucionario. Por supuesto no confiaban en las otras personas y a quienes no eran prí́stas y seguidores de los principios de la Revolución mexicana se les tachaba de traidores, de vendidos, de enemigos del país, eran intolerantes a la pluralidad o diversidad políti. ca, la propia organización sectorial, corporativa, patrimonial fomentaba la desconfianza entre los individuos de las otras clases e incluso de las otras organizaciones. Los entrevistados creían que eran ciudadanos eficaces que eran tomados en cuenta, ideológicamente se sentían parte del sistema, aunque evaluaban muy mal a los políticos y a los policías. El sistema era bueno, el pacto político excelente, para su buen funcionamiento sólo requería de políticos honestos y de expulsar a los traidores sin importar si eran de derecha o de izquierda. Como afirmaba poco después Coleman (1975), los mexicanos estaban preparados para la democracia, pero el sistema de. bía cambiar.

Hasta finales de los años setenta el engendro funcionó, pero tanto la crisis política como la económica que se agudiza en la segunda mitad de los años setenta, impidieron que continuara su reproducción.

Así, a la reforma política (la apertura democrática) se aunó la reforma eco. nómica neoliberal, echando por tierra el sistema de representación y participación política en su conjunto. El sistema democrático se fortaleció y logró que la pluralidad, la competencia partidaria y la alternancia en el plano nacional, en la mayoría de los estados y de los municipios se volviera una realidad; sin embargo, el sistema corporativo, aunque muy debilitado (sobre todo en sus funciones como sindicatos, defensa de los contratos colectivos, salarios, etc.) continuó influyendo tanto como factor de poder sobre las políticas públicas (resistencia a reformas que afectan sus intereses corporativos), como por su intervención en las elecciones locales y estatales (clientelismo, control de bases y desviación de recursos para financiar campañas). De la misma manera en muchos municipios continúa operando el sistema patrimonial y en otros se ha vuelto al antiguo sistema de usos y costumbres que prescinde de los partidos en las elecciones locales, las cuales son realizadas en asambleas comunitarias; la democracia se desarrolla en un entorno muy complica. do.

Ahora el sistema ya no garantiza la representación de estos sectores, aunque lo hace parcialmente el PRI, ahí radica su base electoral más importante. La 
marginalidad perdió sus vínculos políticos y simbólicos con el sistema. En las ciudades los sectores ligados al mercado informal de trabajo (invasores de tierra y asentamientos irregulares, vendedores de calle, transportistas, taxis y bici-taxis, etcétera) se agruparon en organizaciones verticales, autoritarias y violentas que obtienen el amparo de diferentes partidos (mayoritariamente el PRI y el PRD) a cambio de apoyo político. Los vínculos ahora son fundamentalmente instrumentales, carentes de ideología y compromiso simbólico; se apoya a los grupos que gobiernan, sin importar el partido, lo que importa es que tengan el poder de hacer caso omiso de la ley mediante la corrupción, y con ello garantizar su reproducción y a cambio ofrecen clientelas leales; eso sí, sólo mientras su partido tengan el control del gobierno.

Entre los excluidos hay sectores que ni siquiera participan en el mercado informal, son los inútiles para el capital, una especie de nuevo lumpen, formado por pandilleros, vagos que, aislados en getos, no dejan de verse como una amenaza por los sectores integrados. De la misma manera prospera una economía criminal, con vínculos y organización internacionales que operan en el narcotráfico, narcomenudeo, contrabando de mercancías, incluyendo las armas, el tráfico de personas, tanto como emigrantes que van de países en desarrollo a los más desarrollados o como víctimas de comercio sexual y la pornografía. Esta economía criminal rivaliza en montos y poder con la economía de mercado e introduce fuertes distorsiones en la organización social. La sociedad mexicana está fracturada.

Otro cambio fundamental que contribuye al fin del modelo clásico de la dominación priísta es la crisis de la ideología nacionalista y el debilitamiento del estatismo entre la población, que en buena parte sustentaban la cultura política de los mexicanos. Varios factores influyen en ello: en primer lugar, la migración de mexicanos a Estados Unidos y su comunicación con sus parientes, el envió de remesas debilita entre las personas, familias y comunidades implicadas la visión antiimperialista, que era contraparte de la afirmación nacionalista; el proceso de globalización y de apertura comercial e informática cobra sus efectos en México.

En segundo lugar, las políticas neoliberales de apertura comercial y con ello al proteccionismo de la economía. La apertura se consolidó con el Tratado de Libre comercio con Canadá y Estados Unidos. La idea de una nación autónoma, autosuficiente, capaz de sustituir las importaciones, cedió su lugar a la idea de una nación integrada al mundo, interdependiente, capaz de competir y progresar dentro de la globalización, idea que cayó por el peso de las crisis económicas de 1982, 1987 y 1995, pero la idea del aislacionismo ya se había quedado atrás. Ahora la realidad impone la imagen de un país que se margina dentro de la globalización, que se rezaga en los distintos indicadores, que pierde competitividad en el mercado mundial.

En tercer lugar, íntimamente ligado a lo anterior, el achicamiento del estado, su renuncia a continuar interviniendo en la regulación económica, provoca que los 
PONTE, V. M. D. Confianza y eficacia ciudadana en una sociedad con alta desigualdad

salarios caigan, que suba el desempleo y aumente el empleo informal con lo cual se debilita entre la población el estatismo. La opinión muy arraigada de que corres. ponde al estado corregir las desigualdades, resolver los problemas sociales de la población, cedió su lugar a la versión neoliberal, se impuso una crítica sistemática al intervencionismo, al populismo, formulada desde el estado (desde Miguel de la Madrid,1982, hasta nuestros días). El final del discurso nacional estatista significa, en otro plano, la destrucción de la unidad nacional, del pacto nacional revoluciona. rio que alentaba la esperanza de las masas de que sus problemas serían resueltos desde arriba.

En cuarto lugar, el nacionalismo fue golpeado por el surgimiento de los mo. vimientos indígenas por la autonomía de los pueblos, su reconocimiento dentro de un estado multicultural, que arranca a finales de los años setenta y que alcanza su punto más relevante con el levantamiento del EZLN el primero de enero de 1994, el reconocimiento del derecho de los pueblos indígenas a ser tales, a tener autonomía a que se respeten sus tradiciones de gobierno, etcétera, puso fin a la política de unidad racial del nacionalismo, al mestizaje, que fue predominante en toda la histo. ria del México independiente. Como un elemento adicional encontramos en la emigración de indígenas a Estados Unidos, el surgimiento de comunidades indígenas binacionales, especialmente entre los mixtecos de Puebla y Oaxaca, dando una nueva pluralidad a la composición cultural de los mexicanos. La heterogeneidad étnica y cultural finalmente ganó la luz en el espacio público y, la pretensión de la unidad mestiza se terminó.

En quinto lugar está el proceso democrático que rompe con la unicidad par. tidaria, con la exclusión de los otros y su trato de traidores, la pluralidad rompe la identidad entre la nación y el PRI: ser mexicano ya no se reduce a abrazar los li. neamientos de la Revolución mexicana, ahora hay una multiplicidad de proyectos, la izquierda y la derecha democráticas ganan legitimidad y los mexicanos pueden elegir.

El fin del nacionalismo no se tradujo, como cabía esperar, en el surgimiento de un individualismo generalizado, el cual sólo prosperó entre los sectores medios, pero no así entre las comunidades indígenas que se fortalecieron, ni entre los trabajadores del mundo de la informalidad o en sus barrios empobrecidos y sujetos a procesos de disolución de los social, en los cuales se incremento de la violencia, y el pandellerismo; tampoco floreció entre los sectores medios precarizados, a quienes domina la ansiedad y la destrucción de su mundo cotidiano. En lugar del individualismo que los clásicos asociaban a la democracia, nos encontramos frente a una sociedad en proceso de desorganización y fragmentación.

Un elemento que acompaña este proceso de cambio de la sociedad y que quizás es el único que logra dar sentido a la sociedad son los medios de comunicación, en especial la televisión. Sin embargo, sus contenidos y mensajes son una 
mezcla del tradición, como en las telenovelas que repiten hasta el cansancio el mismo modelo maniqueo de buenos y malos y de pobres al final bienaventurados, junto con programas y series, producidas en Estados Unidos, con valores propios de esa sociedad, como el individualismo o el consumismo; con programas deportivos que aprovechan toda oportunidad para reafirmar el espíritu chovinista y nacionalista, finalmente los noticiarios basados en la nota roja y en el escándalo político que poco educan o muestran un patrón cultural definido para el país.

En estas condiciones es muy difícil pensar que el simple proceso de democratización pueda introducir cambios en la cultura política, en especial en fomentar la confianza interpersonal y entre las instituciones, así como mejorar la eficacia ciudadana.

\section{Los cambios en la cultura política y su significado}

En otros textos ya examinamos como evolucionó la cultura política mexicana especialmente entre los años 1993 y el 2001. En 1993 encontramos que aún existía un amplio consenso autoritario, las personas entrevistadas se mostraban más apegadas al autoritarismo que a reglas democráticas para calcular su acción política; asimismo, observamos que la participación en asociaciones voluntarias se asociaba a un reforzamiento de la cultura local, lo más relevante era que las asociaciones reforzaban un sistema y no lo modificaban (SMITH y DURAND, 1995, p. 329). EI cambio cultural aún era incipiente. Veíamos que la transición se reflejaba en la información, ya que claramente había una diferencia en la cultura de los entrevistados con mayor escolaridad y que residían en las ciudades mayores. La desigualdad mostraba sus efectos conservadores en los sectores bajos y la ciudadanía eficaz ganaba fuerza en los sectores mejor ubicados en la escala social. Los datos acerca de la confianza en las instituciones mostraban que era mayor en los estratos menos favorecidos de la sociedad; entre quienes tenían menos escolaridad y vivían en zonas rurales, el sistema se arraigaba entre los pobres, entre los menos eficaces, la confianza se daba a las instituciones del viejo régimen.

En el segundo texto citado estudiamos los cambios ocurridos entre los años 1993 y 2001, periodo en el cual ya se había dado la transición en términos electora. les; el PRI había perdido la mayoría en la Cámara de Diputados (1997) y había perdido la Presidencia de la República (2000); la pluralidad había cobrado cartas de naturalidad y el consenso democrático avanzó, sin alcanzar el consenso democrático (75\%); sin embrago, en el periodo también se incrementó el sector que prefería un gobierno autoritario, el cambio no era lineal (DURAND, 2004).

Respecto de la opinión acerca de la eficacia ciudadana encontramos un aumento, pues se pasó de 20\% que en 1993 consideraban que eran eficaces (tenían 
los medios para decirle al gobierno lo que piensan, que eran escuchados por los funcionarios del gobierno, que era capaces de entender a la política y al gobierno) a $30 \%$ en el 2000; sin embargo, la proporción de la población continúa siendo pequeña. En la comparación quedó claro que hay una correlación negativa entre la evaluación de las instituciones políticas y la eficacia ciudadana. Lo que nos permitió formular la hipótesis de que la eficacia ciudadana está limitada más por el sistema, por su operar deficiente y refractario a la participación ciudadana. Es obvio que la escolaridad muestra importantes efectos sobre la eficacia ciudadana, pero dada la gran desigualdad, la pequeña proporción que tiene estudios universitarios, su efecto es limitado, pero el buen funcionamiento del sistema podría acelerar el proceso.

En cuanto a la confianza interpersonal no se consideró en 1993, pero sí en 2000 , los resultados son muy conocidos: los que creen que se puede confiar en la mayoría de las personas alcanzan $25 \%$, lo cual significa que la gran mayoría es desconfiada; desde luego no aparecen valores tan bajos como en Brasil (3\%), pero está muy lejos de los de Noruega (60\%) (DURAND, 2004, p. 123). Debemos aceptar que las personas se relacionan entre ellas con base en la desconfianza, que resuel. ven la complejidad de la vida cotidiana basados en ese principio.

En lo referente a la confianza en las instituciones encontramos, entre 1993 y 2000, un aumento en la desconfianza en todas ellas desde la familia hasta la justicia y los jueces. Pese a la democratización y quizá, gracias a ella, la desconfianza avanzó. Desagregamos a las instituciones en tres conjuntos factoriales, el primero agrupó a las sociales, el segundo a las políticas y el tercero a los medios de comu. nicación. La gran caída en la confianza se dio en las instituciones políticas, luego en los medios y finalmente las instituciones sociales. Si consideramos la alta confianza las instituciones políticas agrupa sólo a 9,5\%, los medios el 10,3\% y las institucio. nes sociales el 46,4\%; hay una diferencia clara que debe apuntar a comportamien. tos sistémicos bien diferenciados (DURAND, 2004, p. 130). Los mexicanos nos movemos más confiados entre las instituciones sociales (familia, iglesia, escuela y maestros y las organizaciones campesinas o indígenas); en cambio entre los medios (periódicos y revistas, radio y televisón) predomina la desconfianza y en las instituciones políticas (gobierno, jueces y justicia, diputados y senadores y policías) parece absoluta. ${ }^{3}$ Aun cuando en el índice general (conjunto de todas las instituciones) priva la desconfianza no podemos generalizar, pues parece obvio que los mexicanos confiamos bastante más en las instituciones sociales.

\footnotetext{
${ }^{3}$ Hay dos instituciones que son más difíciles de calificar: los empresarios y los sindicatos que factorial. mente están agrupados con los políticos, pero con cargas más bajas, y los militares que están divididos teniendo cargas intermedias en los factores político y social. Esta institución parece escapar el descrédi. to de las instituciones políticas, posiblemente por su carga simbólica y su presencia social cuidando poblaciones victimadas por desastres naturales.
} 
Cuando relacionamos la confianza interpersonal con la otorgada a instituciones encontramos la independencia entre las variables. Nos sorprendió la carencia de asociación entre la confianza interpersonal y la dada a las instituciones socia. les, pues muestra al parecer dos sistemas de referencia diferentes. No hay confianza en las personas fuera de las instituciones sociales, parece haber un comunitarismo o un privilegio a las instituciones primarias o más cercanas a las personas, pero no a las personas en abstracto o a las otras instituciones.

La única asociación positiva que encontramos fue la que se refiere a la parti. cipación en asociaciones sociales y la confianza interpersonal, lo cual confirma la tesis de Putnam (1993). Restaría conocer si en el caso mexicano, como en el de otros países, la participación en asociaciones también ha disminuido, en especial en los sectores excluidos socialmente y, en consecuencia, agravado la crisis de confianza interpersonal.

Respecto de la relación con las variables socioeconómicas (sexo, edad, tamaño de la ciudad, escolaridad, ingreso y clase social), encontramos una ausencia de correlaciones con la confianza en las instituciones y con la confianza interperso. nal. No existe, como en el caso de la eficacia ciudadana, una influencia de la escola. ridad o el tamaño de la ciudad. La confianza aparece como un producto más sistémico y de larga data.

La confianza interpersonal parece tener determinantes muy amplios, que tienen que ver con el conjunto del funcionamiento de la sociedad, sobre todo de la capacidad de prever las respuestas a la acción social, la reciprocidad en acciones tanto a distancia como en las de cara a cara. La ambigüedad, la falta de certeza en las respuestas, sobre todo con los de arriba, con los poderosos, con los funcionarios y políticos, pero también con el comerciante, el prestador de servicios, etcétera, es el mayor enemigo de la confianza. Si el agente no puede predecir con un mínimo de certidumbre la acción racional, basada en reglas, por el contrario debe contemplar la posibilidad de que una vez responda apegándose al derecho o a reglas racionales y en la otra lo haga arbitrariamente, abuse, se aproveche, entonces la desconfianza es la única posibilidad de simplificar la complejidad del entorno.

En cuanto a la confianza en las instituciones políticas encontramos una asociación muy interesante, el desempeño del gobierno, del funcionamiento de la democracia, y de la representación de los legisladores, con la confianza en las instituciones. Asimismo hay una asociación entre el orgullo nacional y la confianza institucional, lo cual nos muestra especies de círculos causales: sí se tiene orgullo de ser mexicano, se acepta el desempeño del gobierno y la representación de los legisla. dores y se valora el desempeño de la democracia entonces crece la confianza. Esta relación se especifica según la ideología del entrevistado, los que se autodefinen de izquierda muestran un círculo negativo, mientras que los que se dicen de derecha son más positivos. Hay en efecto un proceso de crítica del sistema o de su acepta- 
PONTE, V. M. D. Confianza y eficacia ciudadana en una sociedad con alta desigualdad

ción. Hay claramente un proceso político que da sustento a la pluralidad y a la lucha, a la competencia política y finalmente a los procesos electorales. Hay una determinación dentro del sistema político que tiene que ver con ideología, con creen. cias, con experiencias dentro del sistema político, determinación que es autónoma, relativamente, de otras influencias.

Los resultados que hemos recordado nos muestran que la desconfianza es lo que nortea las relaciones entre las personas y de estas con las instituciones. La relación entre democratización y confianza que presentamos no es desechable, lo que impide de que ella se realice son, entre otros, los efectos de la desigualdad social y su intromisión en funcionamiento del sistema político, vía el clientelismo, el incremento de la ilegalidad y la violencia ligadas al comercio informal e ilegal, por ello creemos que el especificar el análisis de la relación entre desigualdad, eficiencia y confianza puede ayudarnos a comprender mejor la dinámica en que estamos sumergidos.

\section{A manera de conclusión}

En nuestros trabajos anteriores manejamos la hipótesis de que la democratización del sistema político mexicano traería cambios significativos en la cultura política de los mexicanos. De acuerdo con los planteamientos de Moisés (1993) y otros autores, pensamos que la consolidación democrática requeriría de esos cam. bios. Los datos nos mostraban, como aquí hemos recordado, que se había iniciado la destrucción de los elementos centrales de la cultura política autoritaria mexicana, en especial había una visión más crítica de la democracia como régimen, ya no se acepta que régimen hubiese sido democrático sólo por que estaba escrito en la Constitución política y lo defendieran los gobiernos y políticos priístas en turno y tampoco se cree que el actual régimen (en 2002) lo sea plenamente. Encontramos una caída en el interés en la política, en la participación (disminuyeron mucho los militantes partidarios y los acarreados), en la confianza en todas las instituciones; había una mayor tolerancia social (papel de las mujeres y de los homosexuales) y una clara pluralidad política, aunque la tolerancia a los diferentes políticamente no fuese tan amplia como la social. En general, detectamos un proceso de cambio de una cultura propia del régimen autoritario hacia uno democrático. Ahora ya no estamos tan seguros de ello, quizás hay que replantear ese punto de llegada; ciertamente estamos dejando atrás la vieja cultura autoritaria, pero el futuro es más incierto.

Este replanteamiento tiene que ver más con el desorden social que acompaña a la globalización y al nuevo capitalismo que con el proceso de la consolidación del régimen político. Éste proceso es alterado por el crecimiento de la desigualdad 
social y de la anomia que la acompaña y por las limitaciones que encuentra el estado para hacer frente a los nuevos reclamos de representación, de participación de los distintos sectores, por un gobierno cuyo apoyo político decrece, que sufre la falta de confianza en la política y en los políticos, y por la incapacidad de las instituciones, por una gobernanza limitada. En consecuencia, la baja eficacia ciudadana se agudiza, tiende a que se incremente el apoliticismo, la falta de participación racional o razonada, y se prepara el terreno para el regreso del carisma, del líder.

Estamos frente a un círculo vicioso en donde se reproduce la desigualdad social, la anomia, la pérdida de eficacia ciudadana, en donde la desconfianza se presenta como el mecanismo funcional que permite resolver la complejidad y la falta de diferenciación de los sistemas.

\section{Referências Bibliográficas}

ALMOND, G.; VERBA, S. The civic culture, political attitudes and democracy in five nations, Princeton: Princeton University Press, 1963.

BAUMAN, Z. Trabajo, consumismo y nuevos pobres. Barcelona: Gedisa, 2000.

BECK, U. Un nuevo mundo feliz. La precariedad del trabajo en la era de la globalización. Argentina: Paidos, 2000. La sociedad del riesgo global. Madrid: Siglo XXI, 2002.

CASTEL, R. As metamorfoses da questão social. Una crônica do salário. São Paulo: Vozes, 2001.

COLEMAN, M. K. The capital city electorate in Mexico's accion nacional: some survey evidence on conventional hypothesis. Social Science Quarterly, v. 56, p. 502-509, dic. 1975.

CONVERSE, P. The nature of belief system in 'Mass Publics'. In: APTER, D. (comp.). Ideology and discontent. New York: The Free Press of Glencoe, 1964. 
DALTON, R. J. Democratic challenges, democratic choices, the erosion of political support in advanced industrial democracies. Oxford: University Press, 2005.

DE GIORGI, R. Redes de inclusión. In: CASTAÑEDA, F. S.; CUELLAR V., A. (coord.). Redes de inclusión. La construcción social de la autoridad. México: Facultad de Ciencias Políticas y Sociales, 1998.

DURAND PONTE, V. M. Ciudadanía y cultura política en México, 1993 - 2001. México: Siglo XXI, 2004.

HARDT, M.; NEGRI, A. Império. Buenos Aires: Paidós, Estado y Sociedad, 2004.

KOWARICK, L. Vulnerabilidad social y económica: trayectorias del tema en Estados Unidos, Francia y Brasil. In: MÓLGORA, M. A. C.; ASSIES, W. Ciudadanía, cultura política y reforma en América Latina XXIII. Coloquio de Antropología y Historia Regionales, Zamora, El Colegio de Michoacán, 24-26 octubre de 2001, p. 103-141.

Escritos urbanos. São Paulo: Editora 34, 2000.

LUHMANN, N. Confianza. México: Anthropos y Uia, 1996.

MOISÉS, A. Democratización y cultura de masas en Brasil. Revista Mexicana de Sociología, México, 1993.

MORÁN, M. L.; BENEDICTO, J. La cultura política de los españoles, un ensayo de reinterpretación. Madrid: Centro de Investigaciones Sociológicas, 1995.

NORRIS, P. La participación ciudadana: México desde una perspectiva comparada. In: SEGOB. Deconstruyendo la ciudadanía. Avances y retos en el desarrollo de la cultura democrática en México. México: SEGOB/Miguel Ángel Porrúa, 2002, pp. 307-359.

PNUD. La democracia en América Latina, hacia una democracia de ciudadanas y ciudadanos. Buenos Aires: Alfaguara, 2004. . Informe sobre desarrollo humano 2005. México: PNUD y Ediciones Mundi Prensa, 2005.

PUTNAM, R. D. Making democracy work: civic tradition in modern Italy. Princeton: Princeton University Press, 1993. Las citas corresponden a la traducción portugesa de Luis Alberto Monjardim: Comunidade e Democracia: a experiência da Itália moderna. Rio de Janeiro: Fundação Getulio Vargas, 1996. 
Solo en la bolera. Colapso y resurgimiento de la comunidad norteamericana. Barcelona: Galaxia Gutemberg, 2002.

(coord.). El declive del capital social. Un estudio internacional sobre las sociedades y el sentido comunitario. Barcelona: Galaxia Gutemberg/Círculo de lectores, 2003.

ROSANVALLON, P. El pueblo inalcanzable. Historia de la representación democrática en Francia. México: Instituto Mora/Colección Itinerarios, 2004.

SEN, A. Desenvolvimento como liberdade. São Paulo: Editora das Letras, 1999.

SMITH, M. M. M.; DURAND PONTE, V. M. La acción colectiva y su papel contradictorio en la construcción de la ciudadanía en México. Estudios Sociológicos, México, El Colegio de México, v. 13, n. 38, p. 309-339, 1995.

Recebido para publicação em março de 2006. Aprovado para publicação em julho de 2006. 